\title{
Pseudomonas poae-Associated Fatal Septic Transfusion Reaction, Peoria, Illinois, USA, 2017
}

\author{
Therese S. Woodring, John J. Farrell
}

In the United States, fatal transfusion-transmitted infections from red blood cell units are rare. Although this pattern mostly reflects how inhospitable refrigerated red blood cell units are to contaminant growth, fatalities caused by microorganisms that can grow at storage temperature $\left(4^{\circ} \mathrm{C}\right)$, but not in standard clinical blood cultures at $37^{\circ} \mathrm{C}$, are probably underestimated. We analyzed a fatal red blood cell transfusion in Peoria, Illinois, USA, that occurred in 2017. Samples from the patient's whole blood and the red blood cell unit remained culture-negative during the investigation, despite direct visualization of gram-negative bacilli within the unit immediately after transfusion. We identified the bacteria as Pseudomonas poae, a nonpathogenic pseudomonad carrying multiple coldshock domain protein genes, and confirmed its cold tolerance and inability to grow at $37^{\circ} \mathrm{C}$. Our work indicates transfusion reaction workups need to include testing for psychrophilic organisms, which could explain the cause of other apparently culture-negative transfusion reactions.

$\mathrm{T}$ ransfusion-transmitted infections (TTIs; i.e., the transmission of bacteria, viruses, parasites, or prions through blood product transfusions) are reportable events (1). Although $>5$ million patients in the United States receive red blood cell transfusions each year, fatal TTIs from contaminated red blood cell units number in the single digits annually and arise primarily from Babesia infection in the donor (Table 1). Bacterial colonization of the red blood cell unit is a much rarer event, and viruses and prions, which are the target of most donor history questionnaires and blood product screening tests, have not contributed to reported fatalities in the past decade. The rarity of bacterial contamination reflects vigilant collection practices for all blood products, including skin disinfection and diversion of the first few milliliters of blood from healthy donors, as well as red blood cell refrigeration, which further decreases contamination risk compared with nonrefrigerated blood products, like platelets.

Author affiliations: University of Illinois College of Medicine,

Peoria, Illinois, USA (T.S. Woodring, J.J. Farrell); OSF System

Laboratory, Peoria (J.J. Farrell)

DOI: https://doi.org/10.3201/eid2508.181936
Still, the rate of fatalities resulting from red blood cell contamination, particularly by bacteria, is surprisingly low, given that, unlike platelets, bacterial contamination of red blood cell units is not screened for after collection, apart from a serologic test for syphilis and visual inspection for gross contamination immediately before transfusion (4). Moreover, pathogen inactivation technologies used after collection for plasma and platelets are not yet available for red blood cells (5). This low rate of bacterial contamination might partly reflect how inhospitable the red blood cell unit becomes to contaminating organisms over its 42-day shelf life. Held at only a few degrees above freezing $\left(4^{\circ} \mathrm{C}\right)$, the unit becomes progressively depleted of high-energy substrates, and waste products and reactive oxygen species accumulate at a $\mathrm{pH}$ well below the physiologic $\mathrm{pH}$ range for blood $(6,7)$. Bacteria that can grow to life-threatening numbers in this environment must be capable of surviving these conditions, and the risk for contamination with these organisms within collection facilities is rare enough to pose minimal threat to the blood supply.

Organisms adapted for survival in packed red blood cell units during storage, however, could be missed during evaluations of suspected transfusion reactions in the clinical laboratory by virtue of their specialized growth limitations. For instance, bacteria best suited to survive in a refrigerated red blood cell unit might not grow at $37^{\circ} \mathrm{C}$, the standard temperature for incubation of suspected TTI workups. Yet, these bacteria do not need to grow at this temperature to trigger a fatal septic reaction upon infusion if their inoculum size is large and endotoxin concentration high. The Centers for Disease Control and Prevention National Healthcare Safety Network guidelines for definite TTIs require evidence of the infectious agent in the transfused unit or recipient (Table 2) (8). When standard laboratory testing is used alone, these cases involving cold-tolerant bacteria could be excluded from fatality statistics for TTIs. We present a case report of a death occurring after transfusion with a contaminated red blood cell unit; the investigation required advanced techniques, such as whole-genome sequencing (WGS), to determine the colonizing agent. 
Table 1. Fatalities caused by red blood cell transfusions reported to the US Food and Drug Administration, 2005-2016*

\begin{tabular}{lcc}
\hline Year & No. fatalities & Organisms (no.) \\
\hline 2005 & 1 & Serratia marcescens \\
2006 & 4 & $\begin{array}{c}\text { Babesia microti }(\mathrm{n}=2), \text { Escherichia coli }(\mathrm{n} \\
=1), \text { Yersinia enterocolitica }(\mathrm{n}=1)\end{array}$ \\
2007 & 3 & B. microti \\
2008 & 5 & B. microti \\
2009 & 0 & B. microti \\
2010 & 1 & B. microti \\
2011 & 1 & B. microti \\
2012 & 1 & B. microti $(\mathrm{n}=1)$, Pseudomonas \\
2013 & 2 & fluorescens $(\mathrm{n}=1)$ \\
2014 & 0 & Enterococcus faecium \\
2015 & 1 & B. microti $(\mathrm{n}=2), P$. fluorescens $(\mathrm{n}=1)$ \\
2016 & 3 & B. microti $(\mathrm{n}=16)$, P. fluorescens $(\mathrm{n}=2)$, \\
All & 22 & E. coli $(\mathrm{n}=1)$, Y. enterocolitica $(\mathrm{n}=1), \mathrm{S}$. \\
& & marcescens $(\mathrm{n}=1)$, E. faecium $(\mathrm{n}=1)$ \\
\hline${ }^{*}$ See $(2,3)$. & &
\end{tabular}

\section{Clinical Case}

In 2017, a 56-year-old woman with a history of diabetes mellitus, hypertension, and right femur fracture requiring open reduction and internal fixation with total knee arthroplasty (TKA) was admitted to a hospital in Peoria, Illinois, USA, with leg pain and inability to walk. Her TKA had been complicated 5 months earlier by periprosthetic femur fracture and infection with Corynebacterium striatum and Pseudomonas aeruginosa, which was treated with intravenous vancomycin and cefepime. At admission, she was noted to have purulent drainage from an open right thigh wound above a long plate in her femur (Figure 1), and blood and wound cultures were positive for methicillin-resistant Staphylococcus aureus. She was immediately started on intravenous vancomycin, and operative incision and drainage were performed on day 4 of hospitalization without complications. By the day the TKA prosthetic was scheduled for removal (day 6), her blood cultures were negative for bacterial growth.
Table 2. Centers for Disease Control and Prevention National Healthcare Safety Network criteria for establishing definite transfusion-transmitted infections *

\begin{tabular}{l}
\hline Criteria \\
\hline 1 of the following: \\
Evidence of the pathogen in 1) the transfused component, 2) the \\
donor at the time of donation, 3) an additional component from \\
the same donation, or 4 ) an additional recipient of a component \\
of the same donation \\
AND \\
No other potential exposures to the pathogen be identified for the \\
recipient \\
AND \\
Either evidence that the recipient was not infected with the \\
pathogen before transfusion or evidence that the identified \\
pathogens are related by molecular or extended phenotypic \\
comparison testing \\
${ }^{*}$ See (8).
\end{tabular}

On day 6, medical staff attempted explant of the TKA hardware; however, the procedure needed to be aborted because of excessive blood loss during debridement. Her preoperative hemoglobin concentration dropped from $10.3 \mathrm{~g} /$ $\mathrm{dL}$ to $5.5 \mathrm{~g} / \mathrm{dL}$ within 1 hour of the procedure. She received 3 units of typed and crossed packed red blood cells without complication. Five hours after this transfusion, her hemoglobin rose to $8.4 \mathrm{~g} / \mathrm{dL}$, but a repeat hemoglobin assessment 21 hours later indicated the concentration dropped $(7.0 \mathrm{~g} /$ $\mathrm{dL}$ ), so another red blood cell unit was ordered for her.

Within 5 minutes of starting the final transfusion, the patient became tachypneic; tachycardia developed, and she began to report shortness of breath. According to hospital protocol, the transfusion was stopped immediately. Clerical error and a hemolytic transfusion reaction were excluded by repeat donor $\mathrm{ABO}$ typing, a direct antiglobulin test, and visual inspection of plasma and urine for hemolysis. The red blood cell unit had no signs of hemolysis or breached bag integrity. Despite empiric treatment for an allergic transfusion reaction, the patient continued to exhibit signs of a systemic inflammatory response (heart rate 120-140 beats/min, respiratory rate $35-40$ breaths $/ \mathrm{min}$ ) and required

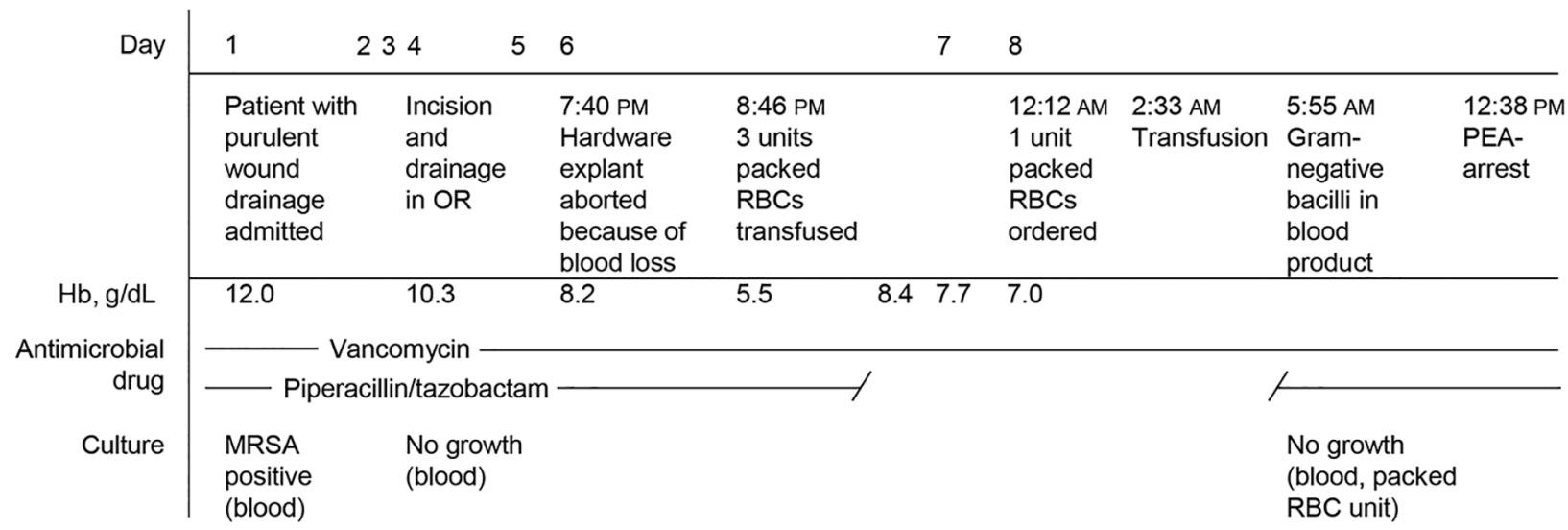

Figure 1. Timeline of patient's hospitalization for periprosthetic joint infection, followed by fatal septic transfusion reaction, Peoria, Illinois, USA, 2017. Hb, hemoglobin; MRSA, methicillin-resistant Staphylococcus aureus; PEA, pulseless electrical activity; RBC, red blood cell. 
increasing oxygen supplementation from a nonrebreather mask and bilevel positive pressure ventilation. Three hours after the transfusion, the laboratory reported gram-negative bacteria throughout smears taken from the red blood cell unit as part of laboratory protocol for suspected transfusion reactions. The patient was started on intravenous piperacillin/tazobactam but continued to deteriorate, undergoing 4 episodes of cardiopulmonary resuscitation before she was declared dead of cardiac arrest 10 hours after the transfusion. Standard $37^{\circ} \mathrm{C}$ clinical blood cultures from both the patient and the red blood cell unit were negative for bacterial growth after 5 days. The transfusion reaction was reported to the Food and Drug Administration 6 days after the patient's death.

\section{Methods}

For blood culture testing, we inoculated a BACTEC Peds Plus (BD, https://www.bd.com) blood culture bottle with $1.0 \mathrm{~mL}$ of blood from the red blood cell unit and left the sample at ambient temperature $\left(25^{\circ} \mathrm{C}\right)$ for $24 \mathrm{~h}$. Using this culture, we streaked organisms onto a blood agar purity plate and incubated for $24 \mathrm{~h}$ at $25^{\circ} \mathrm{C}$. We spotted 1 purified colony for matrix-assisted laser desorption/ionization timeof-flight (MALDI-TOF) mass spectrometry (VITEK MS; bioMérieux, https://www.biomerieux-diagnostics.com) and suspended another colony from the same plate in sterile saline of $0.99 \mathrm{McF}$ arland turbidity standard in preparation for WGS. We extracted DNA from the suspended colony using the QIAGEN REPLI-g UltraFast Mini Kit (https:// www.qiagen.com) according to manufacturer instructions and sequenced with a FLO-MIN 106 SpotON Flow Cell on a Nanopore MinION Mk1B (Oxford Nanopore Technologies, https://nanoporetech.com) using a rapid wholegenome amplification protocol (SQK-RAD004).

We analyzed reads passing the default quality score cutoff of 7 for quality in NanoPlot (9) and assembled de novo using Canu version 1.7.1, an assembler designed for long-read output (10). We evaluated the assessment of the de novo assembly quality using Bandage (11). We retained contigs with $\geq 5 \times$ coverage for further error correction using Nanopolish 0.8.5 with default settings (12) and annotated the final assembly with Prokka 1.13.3 (13). We identified the species by analyzing the 16S rRNA sequence using the Ribosomal Database Project Seqmatch tool and blastn (https://blast.ncbi.nlm.nih.gov/Blast.cgi) within the National Center for Biotechnology Information database. We performed multilocus sequence analysis with 4 conserved gene regions previously used for Pseudomonas taxonomy (16S-gyrB-rpoB-rpoD) on the isolate assembly and 20 fluorescens subgroup genomes available in GenBank (Table 3) (14). For multilocus sequence analysis, we aligned each gene region with MUSCLE before concatenation in Geneious 11.1.5 (15).
Table 3. Pseudomonas spp. included in multilocus sequence analysis to identify bacterial contaminant in red blood cell unit, Peoria, Illinois, USA, 2017

\begin{tabular}{|c|c|c|}
\hline Species & Strain & GenBank accession no. \\
\hline P. poae & $R^{*} * 1-1-14$ & GCA_000336465.1 \\
\hline P. azotoformans & S4 & GCA-001579805.1 \\
\hline P. extremorientalis & BS277 & GCA_900104365.1 \\
\hline P. simiae & WBS417 & GCA_000698265.1 \\
\hline P. palleroniana & MAB3 & GCA_002953635.1 \\
\hline P. tolaasii & $2192 \mathrm{~T}$ & GCA_002072675.1 \\
\hline P. costantinii & LMG 22119 & GCA_001870435.1 \\
\hline P. antarctica & PAMC 27949 & GCA_001647715.1 \\
\hline P. fluorescens & F113 & GCA_000237065.1 \\
\hline P. salomonii & ICMP 14252 & GCA_900107155.1 \\
\hline P. trivialis & IHBB745 & GCA_001186335.1 \\
\hline P. rhodesiae & BS2777 & GCA_900105575.1 \\
\hline P. marginalis & ICMP 9505 & GCA_001467265.1 \\
\hline P. panacis & BS2778 & GCA_900104875.1 \\
\hline P. grimontii & BS2976 & GCA_900101085.1 \\
\hline$P$. veronii & R02 & GCA_002028325.1 \\
\hline P. cedrina & BS2981 & GCA_900104915.1 \\
\hline P. orientalis & F9 & GCA_002934065.1 \\
\hline P. libanensis & BS2975 & GCA_900101035.1 \\
\hline P. synxantha & LBUM223 & GCA_000968415.2 \\
\hline$P$. aeruginosa & PAO1 & GCA_000006765.1 \\
\hline
\end{tabular}

After WGS analysis, we analyzed temperature-dependent viability by incubating isolates from the original blood agar purity plate in BD BACTEC Peds Plus blood culture bottles at $4^{\circ} \mathrm{C}, 25^{\circ} \mathrm{C}$, and $37^{\circ} \mathrm{C}$ for 5 days. We plated cultures diluted 1:100-1:10,000,000 on blood agar and counted the colonies that grew after $24 \mathrm{~h}$ at $25^{\circ} \mathrm{C}$.

\section{Laboratory Investigation}

Initial isolate identification by MALDI-TOF mass spectrometry was split between Pseudomonas fluorescens (50\% confidence) and $P$. veronii (50\% confidence). WGS produced a total of 168,870 reads spanning $885,192,362$ bp that passed the quality threshold. The median read length was 3,200 (maximum 100,184) bp. The assembly contained 2 contigs: a 7,340,165-bp contig with $23.4 \times$ coverage corresponding to the predicted chromosomal length of Pseudomonas spp. (GenBank accession no. CP034537) and a 150,410-bp contig with $41.6 \times$ coverage suggestive of a plasmid (GenBank accession no. CP034538).

Among the 8,602 genes annotated on the chromosome were 6 full-length 16S rRNA genes, consistent with the higher 16S gene copy numbers seen in the P. fluorescens and $P$. putida clusters $(\mathrm{n}=5-7)$ compared with the copy number of $P$. aeruginosa clusters $(n=4)(16)$. The sequence of this gene matched with $>99 \%$ similarity to that of $P$. poae, a fluorescens group pseudomonad, by both the Ribosomal Database Project Seqmatch tool and blastn (Table 4). In multilocus sequence analysis (16S-gryrB-rpoB$r p o D$ ), the isolate also clustered with $P$. poae, further supporting this identification (Figure 2).

The annotated genome contained multiple copies of $\operatorname{cap} B$ and $\operatorname{csp} A$, genes for cold-shock domain proteins that enable efficient translation and long-term cold adaptation 
Table 4. Identification of bacterium in red blood cell unit, Peoria, Illinois, USA, 2017, on the basis of 16S rRNA gene sequencing results, by database

\begin{tabular}{lcc}
\hline Database & Identification & Metric \\
\hline $\begin{array}{l}\text { Ribosomal } \\
\text { Database }\end{array}$ & $\begin{array}{c}\text { Pseudomonas } \mathrm{sp} . \\
\text { VS05_16 }\end{array}$ & 1.000 similarity score \\
Project & P. poae BCHCBZ253 & 0.996 similarity score \\
\hline GenBank & P. poae strain BA2776 & $\begin{array}{c}100 \% \text { coverage, } 99 \% \\
\text { identity }(1,530 / 1,532 \mathrm{nt}) \\
100 \% \text { coverage, 99\% } \\
\end{array}$ \\
& P. poae RE*1-1-14 & identity $(1,530 / 1,532 \mathrm{nt})$ \\
\hline
\end{tabular}

in Antarctic pseudomonads (Table 5) (17). Correlating this genomic signature with phenotypic data, we conducted a temperature-dependent viability experiment that confirmed growth at $4{ }^{\circ} \mathrm{C}$ and $25^{\circ} \mathrm{C}$ (Figure 3 ) and no growth at $37^{\circ} \mathrm{C}$; $>99.9 \%$ of bacteria died within 5 days of incubation at $37^{\circ} \mathrm{C}$. In addition, the annotated genome included evidence of versatile iron-acquisition capacities, including 2 siderophore systems and extracellular heme scavenging (Table 5) $(18,19)$. Fluorescent siderophores are responsible for the fluorescence that gives the fluorescens group its name. Our isolate did demonstrate fluorescence under ultraviolet light, consistent with siderophore production (Figure 4).

\section{Discussion}

WGS analysis identified the organism within the red blood cell unit from this case as $P$. poae, a cold-adapted fluorescens pseudomonad first discovered in the grass phyllosphere in 2003 and since found around the world, including the cold deserts of the Himalayas $(20,21)$. Previous studies of this organism have focused on its potential to promote plant growth through phosphate mobilization, its production of plant-protective antifungal metabolites $(22,23)$, and its ability to remediate contaminated ecosystems through hydrocarbon degradation (24). A Medline search yielded no reports of $P$. poae as a human pathogen. Considering how poorly this isolate tolerated body temperature $\left(37^{\circ} \mathrm{C}\right)$, the lack of clinical cases might reflect a genuinely low virulence in humans.

The pathogenicity of this organism seems specific to the ecology of red blood cell storage and transfusion. On both a genomic and phenotypic level, we found evidence of cold tolerance that particularly suited $P$. poae to not just surviving but thriving in long-term refrigeration in a red blood cell unit. Because the organism grew at $25^{\circ} \mathrm{C}$, any length of improper red blood cell storage at room temperature could have

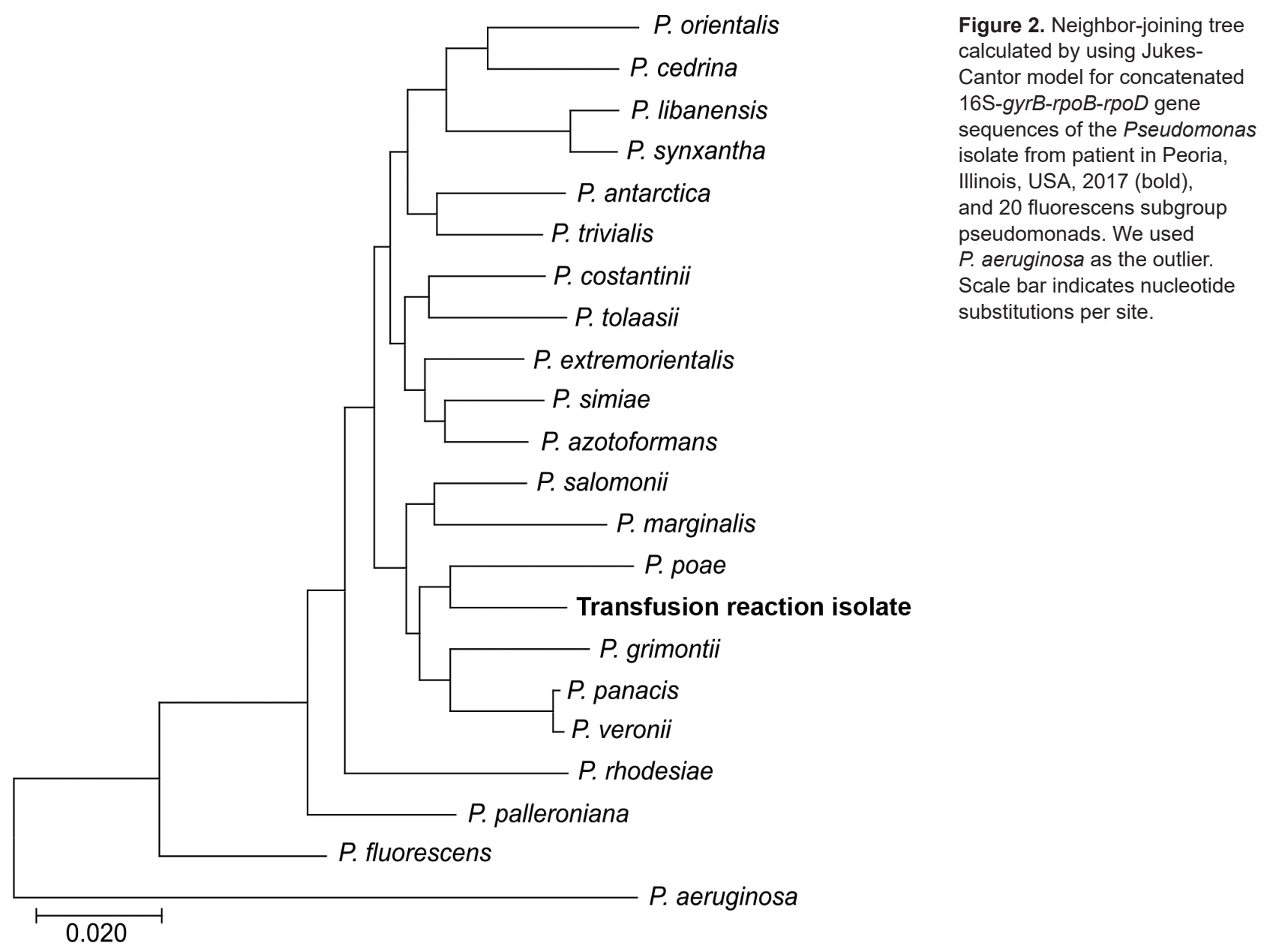




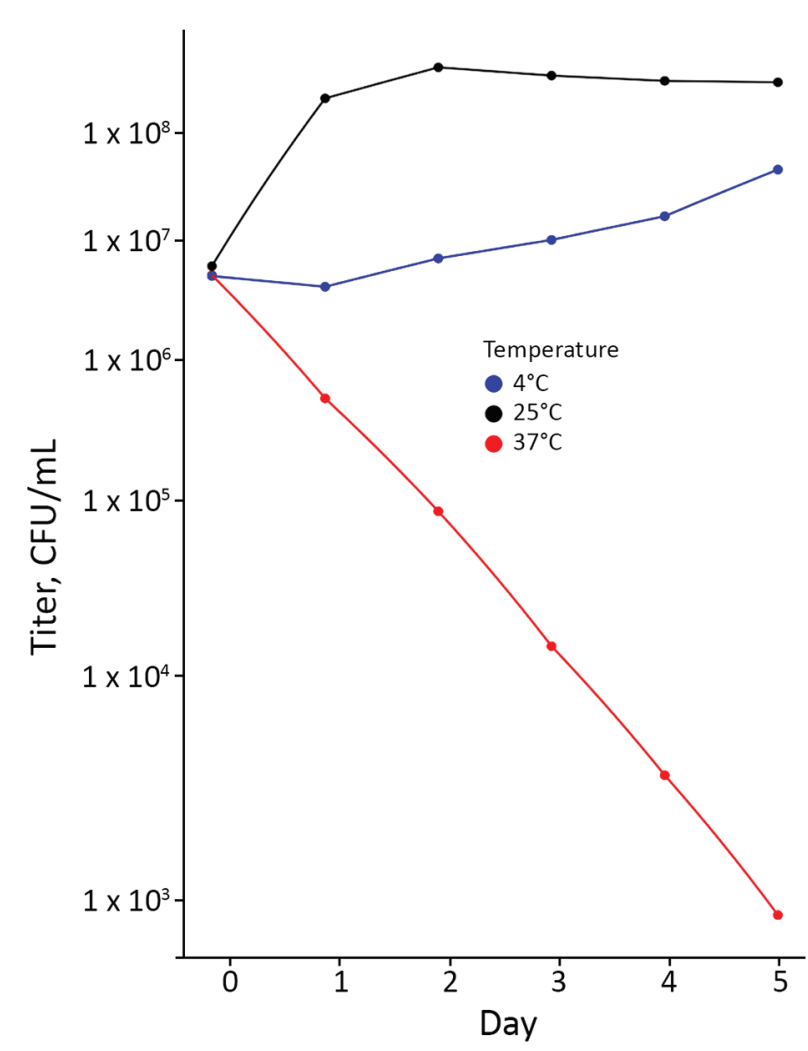

Figure 3. Titers of viable bacteria in cultures of $P$ seudomonas poae from patient in Peoria, Illinois, USA, 2017. Cultures were grown in BD BACTEC Peds Plus (https://www.bd.com) blood culture media incubated at $4^{\circ} \mathrm{C}, 25^{\circ} \mathrm{C}$, and $37^{\circ} \mathrm{C}$ for 5 days.

provided additional opportunity for growth. The versatile iron acquisition capacities suggested by genome annotation indicate the potential for $P$. poae to exploit iron within the red blood cell unit environment (25). Although we cannot specify where the opportunity for colonization arose, $\mathrm{Pseu}$ domonas spp. have been traced to environmental sources, including contaminated water baths and cooling cloths in septic episodes involving blood products $(26,27)$. Pseudomonas spp. are also common reagent contaminants detected in sequencing-based studies (28), suggesting that donor skin and the environment are not the only possible sources of contamination.

Once $P$. poae was introduced into the patient, its survival was likely not required for virulence. Given a sufficiently large inoculum, the endotoxin and other antigens from both live and dead organisms that accumulated during the unit's storage could have provided enough of an immunogenic stimulus within the bloodstream to trigger a massive dysregulated immune response, irrespective of the ability of the organism to establish a sustained infection at $37^{\circ} \mathrm{C}(29)$. Indeed, endotoxin is sufficient to activate multiple innate immune pathways that contribute to the hemodynamic, metabolic, and coagulation defects driving death

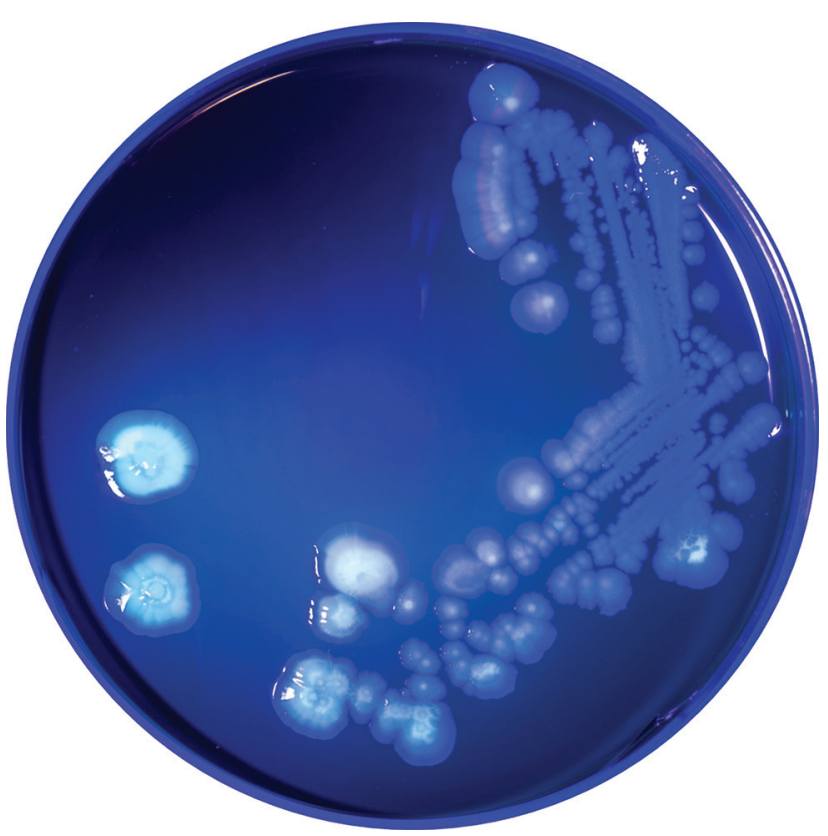

Figure 4. Pseudomonas poae colonies isolated from contaminated packed red blood cell unit, Peoria, Illinois, USA, 2017, fluorescing under ultraviolet light $(\lambda=395 \mathrm{~nm})$.

due to sepsis $(30,31)$. In the case we describe, how the history of methicillin-resistant $S$. aureus sepsis $<1$ week before the infection affected the patient's risk for death is unclear; systemic weakening or modification of the subsequent immune response could have been contributing factors that affected the patient's outcome. Studies of sepsis in animals with previous endotoxin exposure suggest diverging effects of this priming on the basis of the dose $(32,33)$; in vitro, cell wall components of gram-positive bacteria (e.g., lipoteichoic acid) appear to potentiate cytokine responses at low doses of endotoxin and suppress them at high doses (34).

National Healthcare Safety Network criteria for a definite TTI are predicated on pathogen identification, which requires not only a Gram stain, as done in this case, but also a positive blood culture and subsequent isolation on solid media (8). Although standard laboratory testing alone did not meet National Healthcare Safety Network criteria for a definite TTI in this case, we believe the presence of the $P$. poae isolate in the transfused blood product was the cause of death for this patient. The patient's clinical deterioration from hemodynamic stability to death by cardiovascular collapse progressed during the 10 hours immediately after transfusion, and WGS provided postmortem evidence of $P$. poae in the red blood cell unit. Although P. poae is ubiquitous in soil, this patient had no other plausible systemic exposures to this otherwise nonpathogenic organism. In addition, the patient becoming infected with $P$. poae before transfusion was overwhelmingly unlikely; she had received a 6-day course of empiric piperacillin/tazobactam 
covering gram-negative organisms for her periprosthetic infection within 48 hours of the transfusion, and her negative blood cultures before transfusion make any preexisting bloodstream infection with any Pseudomonas spp. highly improbable. Given that we believe the organism caused the patient's death without establishing infection, the more appropriate term in this case would be septic transfusion reaction rather than TTI.

Because of the rapid death of this patient, a patientderived blood sample was not accessible for next-generation sequencing and endotoxin testing, limiting our study. Because P. poae is a ubiquitous plant- and soil-associated organism, we also cannot definitively exclude that the isolate we sequenced was not a contaminant from postmortem handling of the red blood cell unit. However, the absence of these gram-negative organisms (which were visible in blood smears acquired from the blood bag within 5 hours after transfusion) in the standard $37^{\circ} \mathrm{C}$ blood culture is consistent with the temperature intolerance observed for the gram-negative isolate later recovered from the red blood cell unit. Moreover, the growth of this isolate at $4{ }^{\circ} \mathrm{C}$ coupled with the observation that most fatal bacterial TTIs are caused by cold-tolerant gram-negative organisms (e.g., Serratia spp., Yersinia enterocolitica) suggests that the isolate we recovered originated from the refrigerated red blood cell unit (Table 1) (35).

Our case expands the literature on microbially mediated deaths from red blood cell transfusions and represents an extraordinary human fatality from $P$. poae. This episode draws attention to the limitations of standard blood culture procedures to fulfill National Healthcare Safety Network TTI criteria, which, for all practical purposes, require that organisms be incubated under conditions that much more resemble the human body than the cold storage environment selecting for the contaminating organisms. P. poae is a prime example of an organism that could, by virtue of the very temperature-dependent growth that enables its survival in refrigerated red blood cell units, elude detection in a transfusion reaction investigation. Until guidelines expand to include cultures for bacteria that grow at storage temperature, the number of apparently culture-negative adverse transfusion reactions that are caused by similar organisms will remain unknown. Finally, our case demonstrates the potential for next-generation sequencing to detect, identify, and characterize organisms directly from contaminated blood products.

\section{Acknowledgments}

The authors thank the clinical laboratory scientists in the blood bank and microbiology sections of the OSF System Laboratory for their assistance, especially Angie McKeever and Valerie Gosack. We also thank Jim Carlson for photographing the isolate and Trisha Stetzler for her excellent medical care.

\section{About the Author}

Dr. Woodring is a graduate of the University of Illinois College of Medicine in Peoria, Illinois. Her primary research interests include clinical microbiology and incorporating next-generation sequencing into infectious disease diagnostics.

Dr. Farrell is Chair of Infection Control for OSF Saint Francis Medical Center, director of the Serology and Microbiology Laboratories in the OSF System Laboratory, and professor of clinical medicine in the Division of Infectious Diseases for the University of Illinois College of Medicine. His research interests include molecular diagnostics with a focus on detection of bacterial pathogens in culture-negative tissues and body fluids.

\section{References}

1. Centers for Disease Control and Prevention. Blood safety. Diseases and organisms. 2017 [cited 2018 Nov 25]. https://www.cdc.gov/ bloodsafety/bbp/diseases-organisms.html

2. Food and Drug Administration. Transfusion/donation fatalities. 2018 [cited 2017 Nov 18]. https://www.fda.gov/vaccines-bloodbiologics/report-problem-center-biologics-evaluation-research/ transfusiondonation-fatalities

3. Haass KA, Sapiano MRP, Savinkina A, Kuehnert MJ, Basavaraju SV. Transfusion-transmitted infections reported to the National Healthcare Safety Network Hemovigilance Module. Transfus Med Rev. 2019;33:84-91. http://dx.doi.org/ 10.1016/j.tmrv.2019.01.001

4. Kuehnert M, Basavaraju SV. Transfusion-associated infections. In: Bennett JE, Dolin R, Blaser MJ, editors. Mandell, Douglas, and Bennett's principles and practice of infectious diseases. 8th ed. Philadelphia: Saunders; 2015. p. 3351-60.

5. Silverglied AJ. Pathogen inactivation of blood products. 2018 May 23 [cited 2018 Nov 25]. https://www.uptodate.com/contents/ pathogen-inactivation-of-blood-products

6. D'Alessandro A, D'Amici GM, Vaglio S, Zolla L. Time-course investigation of SAGM-stored leukocyte-filtered red bood cell concentrates: from metabolism to proteomics. Haematologica. 2012;97:107-15. http://dx.doi.org/10.3324/haematol. 2011.051789

7. D'Alessandro A, Kriebardis AG, Rinalducci S, Antonelou MH, Hansen KC, Papassideri IS, et al. An update on red blood cell storage lesions, as gleaned through biochemistry and omics technologies. Transfusion. 2015;55:205-19. http://dx.doi.org/ $10.1111 /$ trf. 12804

8. Centers for Disease Control and Prevention. National Healthcare Safety Network biovigilance component hemovigilance module surveillance protocol. $2018 \mathrm{Apr}$ [cited 2018 Nov 25]. https://www. cdc.gov/nhsn/pdfs/biovigilance/bv-hv-protocol-current.pdf

9. De Coster W, D'Hert S, Schultz DT, Cruts M, Van Broeckhoven C NanoPack: visualizing and processing long-read sequencing data. Bioinformatics. 2018;34:2666-9. http://dx.doi.org/10.1093/ bioinformatics/bty 149

10. Koren S, Walenz BP, Berlin K, Miller JR, Bergman NH, Phillippy AM. Canu: scalable and accurate long-read assembly via adaptive k-mer weighting and repeat separation. Genome Res. 2017;27:722-36. http://dx.doi.org/10.1101/gr.215087.116

11. Wick RR, Schultz MB, Zobel J, Holt KE. Bandage: interactive visualization of de novo genome assemblies. Bioinformatics. 2015; 31:3350-2. http://dx.doi.org/10.1093/bioinformatics/btv383

12. Loman NJ, Quick J, Simpson JT. A complete bacterial genome assembled de novo using only nanopore sequencing data. Nat Methods. 2015;12:733-5. http://dx.doi.org/10.1038/nmeth.3444 
13. Seemann T. Prokka: rapid prokaryotic genome annotation. Bioinformatics. 2014;30:2068-9. http://dx.doi.org/10.1093/ bioinformatics/btu153

14. Mulet M, Lalucat J, García-Valdés E. DNA sequence-based analysis of the Pseudomonas species. Environ Microbiol. 2010; 12:1513-30.

15. Kearse M, Moir R, Wilson A, Stones-Havas S, Cheung M, Sturrock S, et al. Geneious Basic: an integrated and extendable desktop software platform for the organization and analysis of sequence data. Bioinformatics. 2012;28:1647-9. http://dx.doi.org/ 10.1093/bioinformatics/bts199

16. Bodilis J, Nsigue-Meilo S, Besaury L, Quillet L. Variable copy number, intra-genomic heterogeneities and lateral transfers of the 16S rRNA gene in Pseudomonas. PLoS One. 2012;7:e35647. http://dx.doi.org/10.1371/journal.pone.0035647

17. Panicker G, Mojib N, Nakatsuji T, Aislabie J, Bej AK. Occurrence and distribution of capB in Antarctic microorganisms and study of its structure and regulation in the Antarctic biodegradative Pseudomonas sp. 30/3. Extremophiles. 2010;14:171-83. http://dx.doi.org/10.1007/s00792-009-0296-5

18. Cornelis P. Iron uptake and metabolism in pseudomonads. Appl Microbiol Biotechnol. 2010;86:1637-45. http://dx.doi.org/10.1007/ s00253-010-2550-2

19. Blin K, Wolf T, Chevrette MG, Lu X, Schwalen CJ, Kautsar SA, et al. antiSMASH 4.0-improvements in chemistry prediction and gene cluster boundary identification. Nucleic Acids Res. 2017;45:W36-41. http://dx.doi.org/10.1093/nar/gkx319

20. Behrendt U, Ulrich A, Schumann P. Fluorescent pseudomonads associated with the phyllosphere of grasses; Pseudomonas trivialis sp. nov., Pseudomonas poae sp. nov. and Pseudomonas congelans sp. nov. Int J Syst Evol Microbiol. 2003;53:1461-9. http://dx.doi.org/10.1099/ijs.0.02567-0

21. Vyas P, Rahi P, Gulati A. Stress tolerance and genetic variability of phosphate-solubilizing fluorescent Pseudomonas from the cold deserts of the trans-Himalayas. Microb Ecol. 2009;58:425-34. http://dx.doi.org/10.1007/s00248-009-9511-2

22. Gulati A, Rahi P, Vyas P. Characterization of phosphate-solubilizing fluorescent pseudomonads from the rhizosphere of seabuckthorn growing in the cold deserts of Himalayas. Curr Microbiol. 2008;56:73-9. http://dx.doi.org/10.1007/s00284-007-9042-3

23. Cho KM, Hong SY, Lee SM, Kim YH, Kahng GG, Lim YP, et al. Endophytic bacterial communities in ginseng and their antifungal activity against pathogens. Microb Ecol. 2007;54:341-51. http://dx.doi.org/10.1007/s00248-007-9208-3

24. Khan AH, Anees M, Arshad M, Muhammad YS, Iqbal M, Yousaf S. Effects of illuminance and nutrients on bacterial photo-physiology of hydrocarbon degradation. Sci Total
Environ. 2016;557-558:705-11. http://dx.doi.org/10.1016/ j.scitotenv.2016.03.068

25. Collard K, White D, Copplestone A. The influence of storage age on iron status, oxidative stress and antioxidant protection in paediatric packed cell units. Blood Transfus. 2014;12:210-9.

26. Brecher ME, Hay SN. Bacterial contamination of blood components. Clin Microbiol Rev. 2005;18:195-204. http://dx.doi.org/10.1128/CMR.18.1.195-204.2005

27. Chaffin DJ, Kuehnert MJ. Pseudomonas fluorescens-related septic transfusion reaction resulting from contaminated cold cloths. Transfusion. 2002;42:41S.

28. de Goffau MC, Lager S, Salter SJ, Wagner J, Kronbichler A, Charnock-Jones DS, et al. Recognizing the reagent microbiome. Nat Microbiol. 2018;3:851-3. http://dx.doi.org/10.1038/ s41564-018-0202-y

29. van der Poll T, van de Veerdonk FL, Scicluna BP, Netea MG. The immunopathology of sepsis and potential therapeutic targets. Nat Rev Immunol. 2017;17:407-20. http://dx.doi.org/10.1038/ nri.2017.36

30. Bryant CE, Spring DR, Gangloff M, Gay NJ. The molecular basis of the host response to lipopolysaccharide. Nat Rev Microbiol. 2010;8:8-14. http://dx.doi.org/10.1038/nrmicro2266

31. Opal SM. The host response to endotoxin, antilipopolysaccharide strategies, and the management of severe sepsis. Int J Med Microbiol. 2007;297:365-77. http://dx.doi.org/10.1016/ j.ijmm.2007.03.006

32. Chen K, Geng S, Yuan R, Diao N, Upchurch Z, Li L. Super-low dose endotoxin pre-conditioning exacerbates sepsis mortality. EBioMedicine. 2015;2:324-33. http://dx.doi.org/10.1016/ j.ebiom.2015.03.001

33. Wheeler DS, Lahni PM, Denenberg AG, Poynter SE, Wong HR, Cook JA, et al. Induction of endotoxin tolerance enhances bacterial clearance and survival in murine polymicrobial sepsis. Shock. 2008;30:267-73.

34. Kim H, Jung BJ, Kim JY, Chung DK. Differential effects of low and high doses of lipoteichoic acid on lipopolysaccharide-induced interleukin-6 production. Inflamm Res. 2014;63:419-28. http://dx.doi.org/10.1007/s00011-014-0714-8

35. Roth VR, Arduino MJ, Nobiletti J, Holt SC, Carson LA, Wolf CF, et al. Transfusion-related sepsis due to Serratia liquefaciens in the United States. Transfusion. 2000;40:931-5. http://dx.doi.org/10.1046/j.1537-2995.2000.40080931.x

Address for correspondence: John J. Farrell, OSF St. Francis

Medical Center, 1224 N Berkeley Ave, Peoria, IL 61603, USA; email: jjf@uic.edu 